\title{
DEVELOPMENT AND CHARACTERIZATION OF BIODEGRADABLE POLYMERIC COMPOSITES BASED ON BUTADIENE-CO-ACRYLONITRILE RUBBER AND FUNCTIONALIZED POST-CONSUMER WOOD WASTE
}

\author{
LAURENTIA ALEXANDRESCU, MIHAI GEORGESCU, MARIA SÖNMEZ, MIHAELA \\ NITUICA, DANIELA STELESCU
}

INCDTP - Division Leather and Footwear Research Institute, 93 Ion Minulescu, 031215, Bucharest, Romania, laurentia.alexandrescu@icpi.ro

\begin{abstract}
In a circular economy, the value of products and materials is maintained as much as possible; waste and resource use are kept to a minimum, and resources do not leave the economic flow once they reach the end of their life, but are reused and create further value. The paper presents the obtaining and characterization of a composite based on butadiene-co-acrylonitrile rubber continuous phase, where are added post-consumer recycled wood particles, with dimensions of $500 \mathrm{~nm}$ - discontinuous phase, and ingredients, such as: active fillers, plasticizers, vulcanizing agents, antioxidants. Wood waste acts as a filling material which leads to the biodegradability of the composite and the decrease in density. The small size of the waste particles and their functionalization with potassium oleate leads to the formation of bonds between the matrix and the particles so that the physical-mechanical characteristics of the composite correspond to the requirements of the products obtained from it.
\end{abstract}

Keywords: biodegradability, polymeric composite, post-consumption, green footwear

\section{INTRODUCTION}

The problem of waste that pollutes the environment has been addressed over the years by several methods: depollution (landfilling, burial, composting, burning), recovery by reuse and/or energy recycling (incineration) and/or mechanical and/or chemical (pyrolysis, gasification, hydrolysis etc.) (Sienkiewicz et al., 2012; JATMA, 2010). The integrated concept of elastomeric waste management, along with these methods, also includes the possibilities of reducing the quantities by using them in biodegradable polymeric materials. Recycling and the use of renewable natural resources offer a new dimension in the discovery of new materials. Recently, special attention has been paid to the development of composites with polymer matrix reinforced with natural fibers instead of conventional composites reinforced with inorganic fibers (glass, carbon, etc.). The development of environmentally friendly "green" materials is conferred by the biodegradability of these natural materials (from various sources), low weight, low cost, high availability, high specific strength compared to glass or carbon fibers, as well as the possibility of adapting existing equipment to processors for mass production (ETRMA, 2011). Composites reinforced with natural fibers are used in a variety of structural applications such as aerospace, automotive components/parts, sports or recreational equipment, craft and office products, equipment, etc. (WBCSD, 2011; RMA, 2011; Naik and Singh, 1991). Wood waste is a set of products and materials whose origin comes from all stages of the wood industry, from logging to the manufacture of finished products. Also, the scrap wood (boxes, crates, pallets) represents a significant quantity (Turku et al., 2017).

Polymer composites are systems that consist of one or more discontinued phases, dispersed in a continuous phase. Thus, at least two different materials, which are completely immiscible, are mixed to form a composite. Additives such as compatibilizers, plasticizers, pigments, temperature stabilizers and UV radiation, nanoparticles are also frequently added in order to improve certain properties. The type

https://doi.org/10.24264/icams-2020.IV.1 
and geometry of the discontinuous phase give the composite optimized properties, such as high specific strength, rigidity and hardness, low specific weight, etc. (Navarro et al., 2004).

The properties of composite materials depend on the compatibility method. For this purpose, the outer surface of the nanoparticles can be functioned with different agents, the most common functionalizing agents being organo-functional siloxanes or sodium oleate. Functionalizing agents are used to improve the adhesion between the polymer matrix and nanoparticles, protect surfaces from internal stresses that can cause cracks, stabilize the interface layer, improve wetting and increase hydrophobicity. In this paper, a composite based on butadiene-co-acrylonitrile-rubber - continuous phase is obtained, in which post-consumer wood waste particles with dimensions of $500 \mathrm{~nm}$ are introduced - discontinuous phase, and ingredients, such as: active fillers, plasticizers, vulcanizing agents, antioxidants.

\section{EXPERIMENTAL}

\section{Materials}

Materials used to obtain the biodegradable polymeric composites were: butadieneco-acrylonitrile with 35\% nitrile, from SAFIC ALCAN; stearin - flakes, white color, molecular weight $284,48 \mathrm{~g} / \mathrm{mol}$; zinc oxide, microparticles, white powder, precipitate 93-95\%; silicon dioxide, molecular mass 60,08 g/mol, white color, particle size $<0,5$ $\mathrm{mm}$; precipitate chalk - white powder, molecular weight 100.09; polyethylene glycol, slightly yellow, $\mathrm{pH}: 5-7$, density: $1.080 \mathrm{~g} / \mathrm{cm}^{3}$; mineral oil, colorless liquid, density: $1.0982 \mathrm{~g} / \mathrm{cm}^{3} ; N$-Isopropyl-N'-phenyl-1,4-phenylenediamine, brown flat granules, molar mass: $226,317 \mathrm{~g} / \mathrm{mol}$, density: $1.04 \mathrm{~g} / \mathrm{cm}^{3}$; sulfur, vulcanization agent (fine yellow powder, melting point: $115^{\circ} \mathrm{C}$ ); tetramethylthiuram disulfide - vulcanization agent (density $1.40 \mathrm{~g} / \mathrm{cm}^{3}$ ), melting point $<146^{\circ} \mathrm{C}$, an ultrafast curing accelerator); all ingredients are from Bayer company.

Wood waste was collected from the manufacture and repair of wooden furniture, cryogenically ground at $12000 \mathrm{rpm}$ for $15 \mathrm{~s}$ and screened through a $500 \mathrm{~nm}$ mesh screen.

\section{Method}

The functionalization of wood waste with potassium oleate was achieved by mixing with a mechanical stirrer with 80 rotations $/$ min with heat, at a temperature of $80^{\circ} \mathrm{C}$ for 8 hours. The ratio between wood waste and potassium oleate - $50 \%$.

\section{Obtaining the Composites}

The rubber is plasticized for $1 \mathrm{~min}$ and $30 \mathrm{~s}$, speed 40 rotations $/ \mathrm{min}$ and $45^{\circ} \mathrm{C}$, mechanically mixed in a Brabender Plasti-Corder PLE-360, then the fillers, plasticizers and wood waste are added, for 4 minutes and $30 \mathrm{~s}$ at 20 rotations $/ \mathrm{min}$ and $45^{\circ} \mathrm{C}$. Homogenized for 2 minutes, speed 60 rotations $/ \mathrm{min}$ and $80-100^{\circ} \mathrm{C}$. The total processing times was 8 minutes. Table 1 shows tested formulations. The mixture is removed from the mixer and finished on the electric roller, by adding the antioxidant and vulcanizing agents. The processing parameters are as following: temperature $23-30^{\circ} \mathrm{C}$, friction of the rollers 1:2, and 50 rotations/min, for $5 \mathrm{~min}$ and homogenization for another $2 \mathrm{~min}$. 
Table 1. Polymeric composites based on polybutadiene-co-acrylonitrile rubber compounded with elastomers functionalized with potassium oleate

\begin{tabular}{|c|c|c|c|c|c|c|}
\hline Ingredients / Symbol & M.U. & B0 & BL1 & BL2 & BL3 & BL4 \\
\hline \multicolumn{7}{|c|}{ Processing on Brabender } \\
\hline $\begin{array}{l}\text { butadiene-co-acrylonitrile } \\
\text { rubber }\end{array}$ & $\mathrm{g}$ & 190 & 190 & 190 & 190 & 190 \\
\hline stearin & $\mathrm{g}$ & 2.28 & 2.28 & 2.28 & 2.28 & 2.28 \\
\hline zinc oxide & $\mathrm{g}$ & 9.5 & 9.5 & 9.5 & 9.5 & 9.5 \\
\hline precipitated chalk & $\mathrm{g}$ & 47.5 & 47.5 & 47.5 & 47.5 & 9.5 \\
\hline silicon dioxide & $\mathrm{g}$ & 57 & 38 & 19 & 0 & 0 \\
\hline PEG 4000 & $\mathrm{~g}$ & 7.6 & 7.6 & 7.6 & 7.6 & 7.6 \\
\hline functionalized Wood waste & $\mathrm{g}$ & 0 & 19 & 38 & 57 & 95 \\
\hline mineral oil & $\mathrm{g}$ & 19 & 19 & 19 & 19 & 19 \\
\hline \multicolumn{7}{|c|}{ Processing on Roller } \\
\hline sulfur & g & 2.85 & 2.85 & 2.85 & 2.85 & 2.85 \\
\hline antioxidant IPPD & g & 5.7 & 5.7 & 5.7 & 5.7 & 5.7 \\
\hline accelerator Th & $\mathrm{g}$ & 1.14 & 1.14 & 1.14 & 1.14 & 1.14 \\
\hline
\end{tabular}

The Brabender mixing diagrams, Figure 1, show that in the first section (A-B) which lasts 1'30" at $40 \mathrm{rpm}$, the elastomer is added into the mixer and therefore the torque initially increases to A. The first loading peak, A, corresponds to the introduction of elastomers. As the torque increases, so does the temperature due to friction. The torque begins to decrease near A to B, mainly due to the homogenization and plasticization of the elastomer, as well as due to the increase in temperature caused by the shear force. Then the other ingredients are introduced and the rotation speed is reduced to $20 \mathrm{rpm}$ for 4'30", and the mixer chamber is kept open. Between point B and point X, the torque begins to increase due to the incorporation of the ingredients, but also as a result of compaction and reinforcement of elastomers. After incorporating the fillers and other ingredients, the second loading peak, $X$, is observed when a maximum torque point appears. The torque starts to decrease, indicating the homogenization of the mixture. Then the homogenization of the compounds occurs for $2^{\prime}$ at $60 \mathrm{rpm}$, with the mixer chamber closed. As a result, a maximum value of torque is obtained due to the compaction and homogenization of the rubber mixture. This is generally followed by a decrease in the value of the torque, which indicates both homogenization of the mixture and increase in the temperature due to friction at a higher rotational speed $(60 \mathrm{rpm})$.

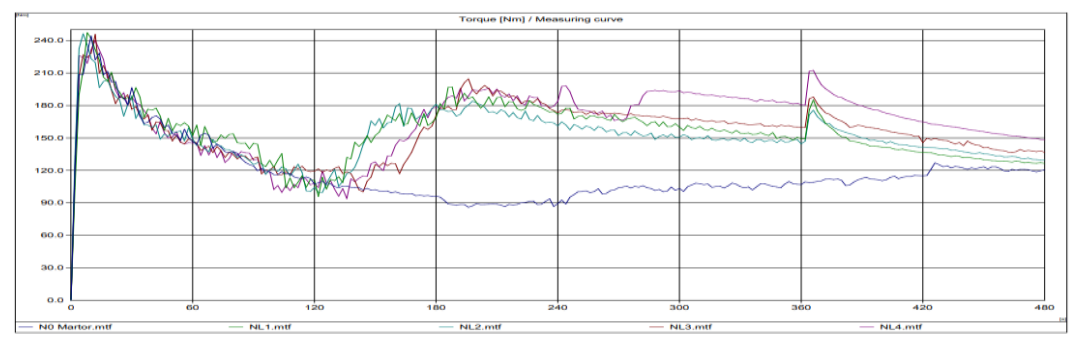

Figure 1. Torque variation vs. the time, recorded at Plasti-Corderul Brabender, when obtaining the rubber composites

It is observed that the control sample has one maximum torque peak, which occurs when the rubber is plasticized. The other two, associated with adding fillers and 
especially wood waste, do not show, instead a slight increase is observed when the mixture is homogenized.

The compounds were then compression-molded (using an electrically heated laboratory press) to obtain a sheet about $2 \mathrm{~mm}$ thick. Press parameters: preheating 3 min.; pressing 4 min.; cooling 13 min.; pressure $300 \mathrm{kN}$; temperature $165^{\circ} \mathrm{C}$. The material was then cooled down to room temperature under the same pressure. The specimens were die-cut from the compression molded sheet and used for testing after 24 hours of storage at room temperature.

\section{Testing Methods}

1. Tensile strength tests of the samples were carried out according to SR ISO 37:2012 using a Schopper Tensile Testing machine 1445, at a constant crosshead speed of $500 \pm 5 \mathrm{~mm} / \mathrm{min}$.

2. Hardness of the samples was measured by Shore "D" Durometer according to SR ISO 7619-1:2011.

3. Abrasion resistance was carried out according to ISO 4649/2010, the cylinder method, using a pressure of $10 \mathrm{~N}$. Abrasion resistance was expressed by relative volume loss in relation to calibrated abrasive paper. A wearing tester with abrasive cloth having granulation of 212-80 mm (PE 80). The samples used were obtained from rolled blends and pressed into sheets, then cutting with a rotating die and have cylindrical shape, with a diameter of $16 \mathrm{~mm}$ and height of min. $6 \mathrm{~mm}$.

4. FT-IR spectroscopy was done using the FT-IR 4200 JASCO, Herschel series instrument, equipped with ATR having diamond crystal and sapphire head within the spectrometric range $2000-530 \mathrm{~cm}^{-1}$.

\section{RESULTS AND DISCUSSION}

The polymer structures obtained, in initial state and after accelerated ageing were characterized in terms of their physical-mechanical properties, and results are presented in table 2. Analyzing the values of physical-mechanical tests reveals the following:

Hardness of the control sample is $57^{\circ} \mathrm{Sh} \mathrm{A}$, when adding the functionalized wood waste increases proportionally with the amount of waste used in the mixture, up to $62^{\circ} \mathrm{Sh} \mathrm{A}$. This is demonstrated by the fact that the hardness increases with the amount of fillers in the mixture.

The tensile strength decreases compared to the control sample, $8.16 \mathrm{~N} / \mathrm{mm}^{2}$, and proportionally to the amount of wood waste introduced into the composite, reaching $1.03 \mathrm{~N} / \mathrm{mm}^{2}$ for the composite with $50 \%$ functionalized wood waste.

Elasticity does not vary compared with control sample.

Table 2. Physical-mechanical characteristics of the composites

\begin{tabular}{llllll}
\hline $\begin{array}{l}\text { Physical mechanical- } \\
\text { characteristics }\end{array}$ & \multicolumn{7}{c}{ B0 } & BL1 & \multicolumn{2}{c}{ BYMBOL } & BL3 & BL4 \\
\hline Hardness, ${ }^{\circ}$ Sh A & 57 & 57 & 58 & 60 & 62 \\
Elasticity, $\%$ & 22 & 22 & 22 & 22 & 22 \\
Modulus 100\%, N/mm ${ }^{2}$ & 0.96 & 1.01 & 1.11 & 0.83 & 0.89 \\
Modulus 300\%, N/mm ${ }^{2}$ & 1.80 & 1.59 & 1.69 & & \\
Tensile strength, N/mm & 8.16 & 6.79 & 2.38 & 1.0 & 1.03 \\
Elongation at break, \% & 660 & 740 & 460 & 280 & 260 \\
\hline
\end{tabular}

https://doi.org/10.24264/icams-2020.IV.1 


\begin{tabular}{llllll}
\hline Residual elongation, \% & 24 & 28 & 20 & 20 & 14 \\
Tear strength, N/mm & 24.13 & 21.92 & 16.42 & 10.33 & 13.71 \\
Specific weight, $\mathrm{g} / \mathrm{cm}^{3}$ & 1.22 & 1.21 & 1.18 & 1.16 & 1.01 \\
Abrasion resistance, $\mathrm{mm}^{3}$ & 142.98 & 181.74 & 180.82 & 264.81 & 400.25 \\
\hline
\end{tabular}

Elongation at break, similar to tensile strength, decreases from $660 \%$ of the control sample, proportional to the amount of wood waste, down to $260 \%$ for the composite with $50 \%$ wood waste in the composition. Similar values are obtained for residual elongation and tear strength.

Density decreases proportional to the amount of wood waste, from $1.22 \mathrm{~g} / \mathrm{cm}^{3}$ control sample to 1.01 in the BL4 sample with $50 \%$ wood waste.

The abrasion increases exponentially with the proportion of wood waste added, thus the control sample has a value of $142.98 \mathrm{~mm}^{3}$, the BL1 sample with $10 \%$ wood waste has the value of $181.74 \mathrm{~mm}^{3}$, and the BL4 sample with $50 \%$ wood waste reaches 400.25 $\mathrm{mm}^{3}$. It was observed that composites with $10-20 \%$ wood waste have values that fall within the standardized requirements for abrasion, namely $200 \mathrm{~mm}^{3}$.

FT-IT spectroscopy. IR spectrum represents the radiant energy absorption curve in the IR domain by the sample molecule, depending on the wave length or radiation frequency. The infrared domain of the electromagnetic radiation is between 0.8 and 200 $\mu \mathrm{m}$. IR domain for usual organic chemistry is between 2.5 and $25 \mu \mathrm{m}$. The structural determinations were carried out on an IR molecular absorption spectrometer with double beam, in the range of 4000-600 $\mathrm{cm}^{-1}$, using 4200 FT-IR equipped with ATR diamond crystal and sapphire head. The solid state samples were set in the ATR and the equipment recorded the transmittance spectra of the sample and then compared it with the background spectra previously recorded. The recorded spectra of the samples were compared with the pure elastomer spectrum. After the tests were carried out, the following were found:

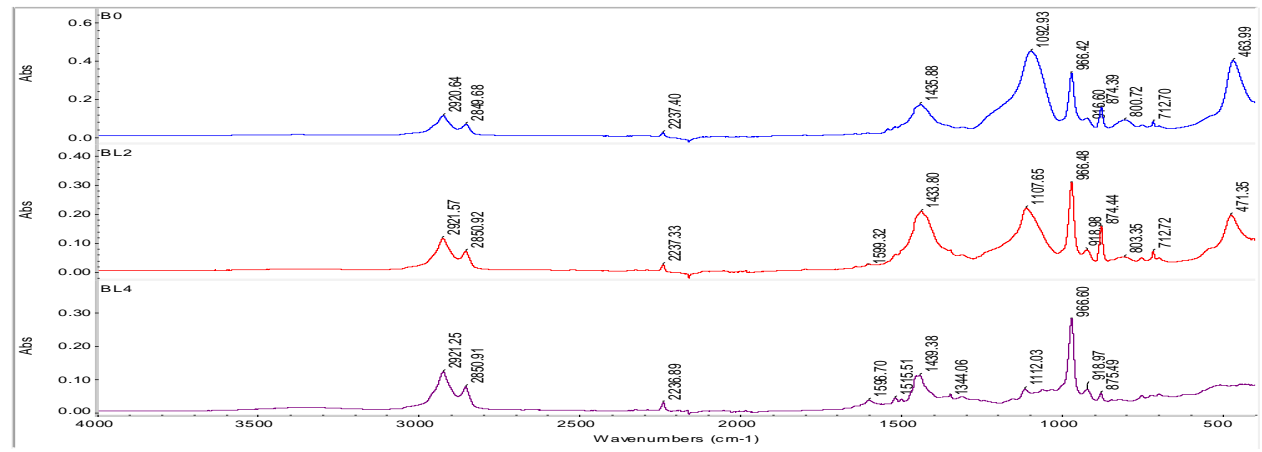

Figure 2. FTIR spectra of composites based on butadiene-co-acrylonitrile rubber / potassium oleate functionalized wood waste

In the case of butadiene-co-acrylonitrile rubber/wood waste treated with potassium oleate composite, in addition to the band's characteristic of the treated waste (especially at $\left.\sim 1596,1515 \mathrm{~cm}^{-1}\right)$ the characteristic band of silica $\left(1090-1100 \mathrm{~cm}^{-1}, \sim 800 \mathrm{~cm}^{-1}, 460\right.$ $\left.470 \mathrm{~cm}^{-1}\right)$, calcium carbonate $\left(\sim 874,712 \mathrm{~cm}^{-1}\right)$ and rubber, can also be observed. Moreover, the presence of wood waste can be proved in BL4 by the fact that the area $1000-1100 \mathrm{~cm}^{-1}$ contains several overlapping strips including the $\mathrm{C}-\mathrm{O}$ band from approximately $1027 \mathrm{~cm}^{-1}$ of the untreated wood waste. In $\mathrm{BL} 2$ due to the presence of $\mathrm{SiO}_{2}$ 
there is a merging of the bands, one characteristic of silica between $1000-1100 \mathrm{~cm}^{-1}$ and the C-OH strips from the wood waste, which leads to an asymmetry of the peak.

\section{CONCLUSION}

The paper presents the study of the new biodegradable polymeric composites, based on wood waste nanoparticles functionalized with potassium oleate dispersed in the butadiene-co-acrylonitrile elastomer matrix. Wood waste (fillers), by dispersing them in the elastomeric matrix, led to a biodegradable polymeric material, with less performance characteristics, which still meets the requirements of the profile standards, but the composite with $50 \%$ wood waste. The specific weight decreases in proportion to the amount of wood waste used to process the composites, which leads to the weight loss of the products. The materials are adapted for applications in "green" biodegradable footwear, with short life after use.

\section{Acknowledgements}

This paper is funded by the Ministry of Research and Innovation within Program $1-$ Development of the national RD system, Subprogram 1.2 - Institutional Performance RDI excellence funding projects, Contract no. 6PFE/2018-PERFORM-TEX-PEL, the LIFE program in the frame of LIFEGREENSHOES 4 ALL (LIFE17ENV/PT/000337) project and PN $19 \quad 17 \quad 01 \quad 03 / 2019$ project: "Biodegradable composites from technological and post-consumption polymeric wastes by designing and applying $4 \mathrm{R}$ eco-innovative technologies (4R-ECO-MAT)".

\section{REFERENCES}

ETRMA - European Tyre \& Rubber Manufacturers’ Association (Belgium) (2010), “A Valuable Resource with Growing Potential”, 2010 edition, http://www.etrma.org/default.asp (May 2011)

JATMA - The Japan Automobile Tyre Manufacturers Association NC (Japan) (2010), "Tyre Industry of Japan 2010”, Report downloaded from: http://www.jatma.or.jp/english/media/ (05.2011).

Naik, T.R. and Singh, S.S. (1991), "Utilization of Discarded Tires as Construction Materials for Transportation Facilities", Report No. CBU-1991-02, UWM Center for By-Products Utilization. University of Wisconsin-Milwaukee, Milwaukee, p. 16.

Navarro, F.J., Partal, P., Martínez-Boza, F. and Gallegos, C. (2004), "Thermo-rheological behaviour and storage stability of ground tire rubber-modified bitumens", Fuel, 83, 2041-2049, https://doi.org/10.1016/j.fuel.2004.04.003.

RMA - Rubber Manufacturers Association (USA) (2009), "Scrap Tire Markets in the United States 9th Biennial Report”, Report downloaded from: http://www.rma.org/scrap_tires/ (May 2011)

Sienkiewicz, M., Kucinska-Lipka, J., Janik, H. and Balas, A. (2012), "Progress in used tyres management in the European Union: A review", Waste Management, 32, 1742-1751, https://doi.org/10.1016/j.wasman.2012.05.010.

Turku, I., Keskisaari, A., Kärki, T., Puurtinen, A. and Marttila, P. (2017), "Characterization of wood plastic composites manufactured from recycled plastic blends", Composite Structures, 161 469-476, https://doi.org/10.1016/j.compstruct.2016.11.073.

WBCSD - World Business Council for Sustainable Development (Switzerland) (2008), "The Report Managing End-of-Life Tyres", Report downloaded from: http://www.wbcsd.org/templates/Template WBCSD5/layout.asp?type=p\&MenuId=MTYwNg\&doOpen=1\&ClickMenu=LeftMenu (05. 2011). 